\title{
Net Energy Intake Rate as a Common Currency to Explain Swan Spatial Distribution in a Shallow Lake
}

\author{
Abel Gyimesi - Sam Varghese • Jan De Leeuw • \\ Bart A. Nolet
}

Received: 24 March 2011 / Accepted: 21 November 2011 /Published online: 19 January 2012

(C) The Author(s) 2012. This article is published with open access at Springerlink.com

\begin{abstract}
Animal distribution is usually predicted from the spatial variation in food biomass, whereas foraging theory commonly uses net energy intake rate as the currency to be maximized. We tested whether net energy intake rate better predicted the distribution and abundance of tundra swans than food biomass. In a shallow lake, we mapped the density of sago pondweed tubers during 2 years, and calculated the foraging benefits and costs to tundra swans. Swan residence was expressed in bird-days, i.e. the sum of daily counts. We used four measures of increasing complexity to predict bird-days per inlet: total food biomass $(B)$, total food biomass above giving-up density $(B+)$, total accessible food
\end{abstract}

\section{A. Gyimesi • B. A. Nolet}

Department of Animal Ecology,

Netherlands Institute of Ecology (NIOO-KNAW),

PO Box 50, 6700 AB, Wageningen, The Netherlands

S. Varghese $\cdot$ J. De Leeuw

Department of Natural Resources, Faculty of Geo-Information Science and Earth Observation (ITC) of the University of Twente, P.O. Box 217, 7500 AE, Enschede, The Netherlands

\section{Present Address:}

A. Gyimesi $(\square)$

Department of Bird Ecology, Bureau Waardenburg,

Varkensmarkt 9,

$4101 \mathrm{CK}$, Culemborg, The Netherlands

e-mail: a.gyimesi@buwa.nl

\section{Present Address:}

S. Varghese

Marine Products Export Development Authority, Panampilly

Nagar,

Cochin, Kerala 682 036, India

Present Address:

J. De Leeuw

International Livestock Research Institute (ILRI),

P.O. Box 30709, Nairobi, Kenya biomass above giving-up density $\left(a B^{+}\right)$, and total achievable net energy intake rate above giving-up energy intake rate $(\mathrm{NEI}+)$. Considering both years, observed bird-days of inlets correlated only with $N E I^{+}$, and not with $B, B+$, or $a B^{+}$. In both years, our predictions of bird-days based on the $N E I+$ model better matched observed relationships than the predictions of the other three models. Our case study suggests that in heterogeneous wetlands, correcting for givingup density, food accessibility and foraging costs may be necessary in order to predict bird distribution and abundance.

Keywords Aggregative response - Carrying capacity . Cygnus columbianus bewickii Stuckenia pectinata .

Remote sensing

\section{Introduction}

Carrying capacity predicts the maximum number of animals an area can support, and is widely used to describe the quality of habitats (Price 1999; Sayre 2008). In the case of stopover sites for migratory animals, the maximum number that can be accommodated depends largely on the amount of food present (Newton 1980; Percival and Evans 1997; Salewski and Schaub 2007). Consequently, carrying capacity calculations are often simply a division of the site's total food stock by the daily food intake of an individual (see review in West et al. 2005). However, there are numerous problems with this approach. Firstly, animals often cease foraging by reaching a certain food density, leaving the socalled giving-up density (GUD) remaining in the foraging patch (Brown 1988; Sutherland and Anderson 1993; Gill et al. 2001b; Goss-Custard et al. 2003). Secondly, part of the food might not be available or accessible to foragers, due to 
limitations in time (e.g., tidal cycles, periodic human disturbance) or space (e.g., food is buried too deep in the sediment) (Zwarts and Wanink 1993; Percival et al. 1998; Gill et al. 2001a). Thirdly, energy costs of foraging can reduce the profitability of foods; for example, diving costs for ducks may limit the use of deep waters (Houston and Carbone 1992; de Leeuw et al. 1999) and probing costs for waders may affect their distribution across different sediment types (Johnstone and Norris 2000).

In conventional foraging models, the currency animals are assumed to maximize is the net rate of energy intake (i.e., intake rate based on accessible food density minus foraging costs; Charnov 1976; Stephens and Krebs 1986). Both accessible food density and the energetic costs of foraging can show considerable spatial variation in wetlands (Kraan et al. 2009), which may affect net energy intake rates (Nolet et al. 2001). Models that ignore any of these problems, may over- or underestimate intake rates, and thus the site's actual carrying capacity (van Gils et al. 2004). Therefore, more complicated models, including the accessibility of resources and costs of foraging, may be necessary to understand animal distribution and abundance at heterogeneous sites.

Here we present a case study that examines the staging of tundra swans (Cygnus columbianus bewickii) in different inlets of a shallow lake in relation to the distribution of their food sources and possible energy benefits and costs. Swans visit the study lake for a few weeks during autumn migration, and forage there exclusively on belowground tubers of sago pondweed (Stuckenia pectinata) (Beekman et al. 1991). At this time, no aboveground plant parts are present (van Wijk 1988), so no direct visual cues reveal the whereabouts and the density of the tuber stands. Tundra swans loosen the sediment by trampling in the water and creating a current. Subsequently, they gather the whirled-up tubers by head-dipping in shallow water or by up-ending in deeper water. Foraging costs are dependent on water depth (i.e. higher in deep water; Nolet et al. 2006) and sediment type (i.e. lower at sandy sediments; Nolet et al. 2001). Both water depth and sediment type also influence the biomass of accessible food (lower at deep and/or sandy sites) (Nolet and Klaassen 2009). The inlets in our study lake exhibited different combinations of food density, water depth, and sediment texture (Beekman et al. 1991; Nolet et al. 2002), providing the opportunity to study the impacts of foraging benefits and costs on swan distribution and abundance.

At migratory stopover sites, turnover of individual migrant birds can be high, and so carrying capacity is generally expressed as the cumulative number of birds ('bird-days') that can be sustained in an area (Goss-Custard 1985). In order to select the best predictor of bird numbers for carrying capacity calculations, we predicted observed bird-days using four measures of increasing complexity: total food biomass $(B)$, total food biomass above a giving-up density $(B+)$, total accessible (i.e. within reach of swans) food biomass above a giving-up density $\left(a B^{+}\right)$, and achievable net energy intake rate above a giving-up net energy intake rate $(N E I+)$. We also estimated total bird-days by a set of functionalaggregative responses (i.e., the distribution of foraging pressures relative to intake rates) under the four predictors, and then compared them to observed relationships.

\section{Methods}

Study Area

Our study area was the Lauwersmeer $\left(06^{\circ} 13^{\prime} \mathrm{E}, 53^{\circ} 22^{\prime} \mathrm{N}\right.$; The Netherlands), a ca. 2,000 ha shallow lake (mean depth $2.1 \mathrm{~m}$ ) that swans visit in October on their migration from the Russian tundra to their wintering grounds in North-West Europe (Beekman et al. 1991). This area was a bay of the Wadden Sea before a dam turned it into a freshwater lake in 1969. We focused on the nine former inlets (Fig. 1) that became vegetated almost exclusively by sago pondweed after the area was impounded (Pot 1984; van Wijk 1988; Hidding et al. 2010). The shallow parts of these inlets, where swans can access the bottom $(<0.8 \mathrm{~m})$, have a total surface area of 1,020 ha.

\section{Mapping of Sediment and Water Depth}

We collected 350 sediment cores $(0.35 \mathrm{~m}$ deep and $0.07 \mathrm{~m}$ diameter) from randomly-selected locations from within shallow parts $(<0.8 \mathrm{~m})$ of the lake, in order to create a sediment texture map. We sub-sampled the layers 0.05 $0.10 \mathrm{~m}$ and $0.20-0.25 \mathrm{~m}$ (measured from surface down) and subjected them to a particle-size distribution analysis (cf. Nolet et al. 2001) using the Malvern analyzer apparatus Mastersizer 2000. We conducted a principal component analysis (PCA) on six particle size categories. We used the first component value to index sediment texture, which explained $60 \%$ of the variation in sediment, and among the six particle size categories it correlated best with the silt fraction $50-63 \mu \mathrm{m}\left(r^{2}=0.93\right)$.

We also measured water depth at 5,315 locations, spread uniformly in the parts of the lake where sago pondweed could potentially grow $(0-1.3 \mathrm{~m}$; van Wijk 1988). We corrected the measurements to the fixed Amsterdam Ordnance Datum level (NAP), using continuous water level measurements collected by water managers (Waterschap Noorderzijlvest). We recorded the geographical position of these sites (and of all further ones) with a Thales Z-Max differential GPS $(<0.2 \mathrm{~m}$ horizontal accuracy). We carried out the sediment mapping with the inverse distance weighting (IDW) interpolation method with weight 2.5 , whereas bathymetry mapping with a weight of 1.5 , to generate values, 


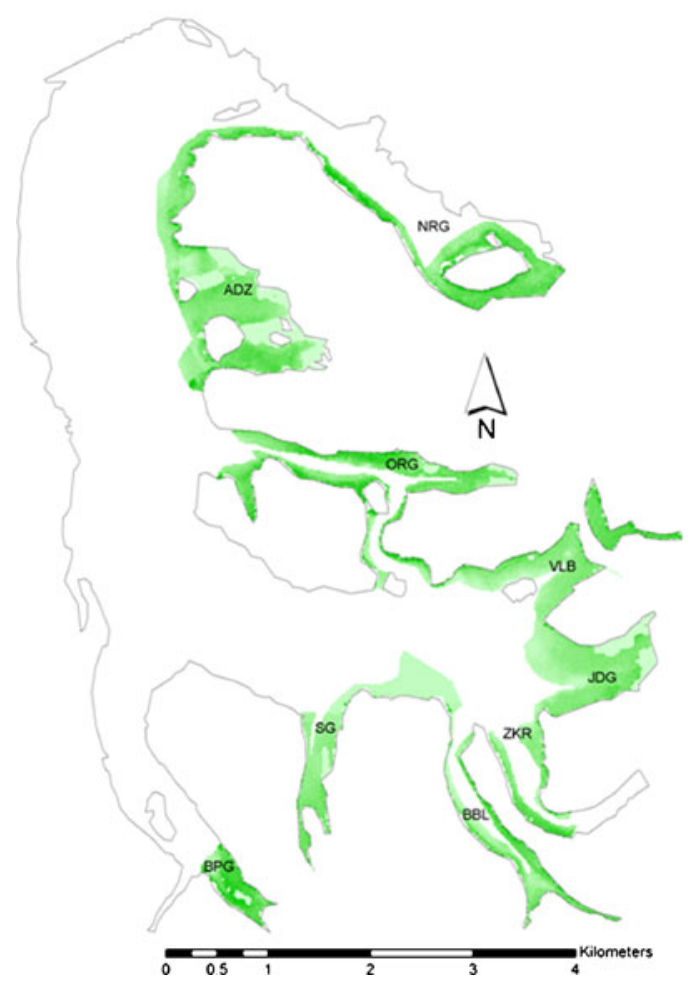

Fig. 1 Map of predicted belowground biomass of sago pondweed in the Lauwersmeer in 2006 (left) and 2007 (right): the darker the coloring, the more biomass (2006: $0-35 \mathrm{~g} / \mathrm{m}^{2} ; 2007: 0-25 \mathrm{~g} / \mathrm{m}^{2}$, dry weight). The deep parts of the lake $(>1.5 \mathrm{~m})$ are excluded from the analyses and

using ArcGIS 9.2 (ESRI, Redlands, USA), specific for the satellite image pixels (see below).

\section{Mapping of Plant Biomass}

Core sampling of belowground tuber biomass of sago pondweed is labor-intensive, and not a suitable method to map tuber biomass at the scale of the Lauwersmeer. Instead, we made use of the finding that, at least under controlled conditions, tuber biomass in autumn is positively and linearly related to peak submerged biomass (i.e., aboveground green matter) in the preceding summer (Hangelbroek and Santamaría 2004). Therefore, we estimated tuber biomass using satellite imagery of the submerged aboveground biomass earlier in the year.

First, in 2006, we sampled both green aboveground plant biomass $(P)$ and tuber biomass density $(D)$. Between 26 and 30 July, we collected aboveground biomass from seventy seven $1 \mathrm{~m}^{2}$ plots. Later, in October, we re-sampled tuber biomass within a $0.3 \mathrm{~m}$ perimeter around these $1 \mathrm{~m}^{2}$ plots by taking 12 cores ( $0.1 \mathrm{~m}$ in diameter) from the upper $0.35 \mathrm{~m}$ of the sediment. We dried all samples for at least $48 \mathrm{~h}$ on $60^{\circ} \mathrm{C}$ to obtain dry mass $\left(\mathrm{g} / \mathrm{m}^{2}\right)$. We then used a geometric mean regression (Ricker 1984) to relate aboveground biomass and tuber biomass density under field conditions.

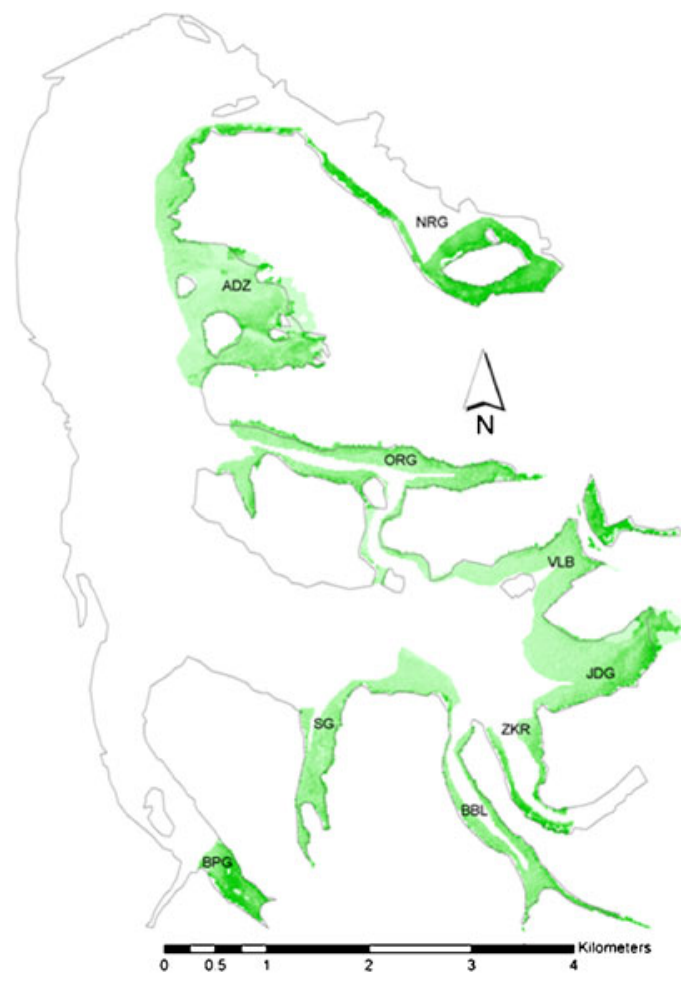

left blank. The inlets are indicated by abbreviations: ADZ: Achter de Zwarten, BBL: Babbelaar, BPG: Blikplaatgat, JDG: Jaap Deensgat, NRG: Nieuwe Robbengat, ORG: Oude Robbengat, SG: Simonsgat, VLB: Vlinderbalg, ZKR: Zoutkamperril

Also in 2006, we acquired an ASTER satellite image at 25 July (i.e., the time of peak biomass). We extracted per pixel $(15 \times 15 \mathrm{~m})$ the Normalized Difference Vegetation Index (NDVI: a numerical indicator for green vegetation, calculated from spectral reflectance in the red and near-infrared wavelengths). We then used the Gaussian logit curve, described by Huisman et al. (1993) as model type IV, to predict aboveground biomass density per pixel, after correction for water depth at each pixel (parameter values: $a=5.77, b=0.00, c=$ $2.47, \mathrm{~d}=-0.18, \mathrm{e}=0.01, \mathrm{f}=-0.19)$. Finally, we predicted $D$ from $P$ per pixel using the geometric mean regression of the field data, in ArcGIS 9.2. We validated predictions using direct tuber biomass data from 20 locations that were additionally sampled in October 2006.

On 2 June 2007 (again at peak biomass), we acquired another ASTER image. In that year, we did not sample aboveground biomass, but instead used the spectral image to parameterize $(a=2.00, b=-14.06, c=37.49, d=-10.11$, $\mathrm{e}=10.92, \mathrm{f}=18.56)$ the logit curve described by Huisman et al. (1993), and thus predicted belowground biomass density directly per pixel from the spectral image. We validated the model using 90 tuber biomass field samples collected in October 2007. To improve accuracy, we collected cores from larger $(12 \times 12 \mathrm{~m})$ sampling plots. Within each plot, we created four $4 \times 4 \mathrm{~m}$ quadrats, measured from the corner 
points. We took one sampling core at the corners of each quadrat, providing a total of 16 cores per plot, but collected as four subsamples. During the interpretation, we weighted the subsamples according to the extent the sampling quadrate fell within the satellite image pixel.

\section{Measure of Swan Residence}

During the period swans were present at the Lauwersmeer (October-November), we counted birds daily at each inlet using $10 \times$ binoculars and 20-60× telescopes, also recording the number of swans foraging. We summed counts per inlet to generate bird-days.

\section{Prediction of Net Energy Intake}

We developed pixel-specific predictions of achievable net energy intake rate using ArcGIS 9.2, based on a modified version of the functional response reported by Nolet and Klaassen (2009). This model considers the metabolizable energy intake rate and energy expenditure of tundra swans while foraging on sago pondweed tuber biomass:

$n e i(d, s)=\varphi(s) \cdot q \cdot e \frac{a(s) D(d)}{\left(1+a(s) \cdot t_{h} \cdot D(d)\right)}-c(d, s) ;$

where $n e i(d, s)$ is the net energy intake rate while foraging $(\mathrm{J} / \mathrm{s})$ as a function of water depth $d$ and sediment type $s ; q$ is the assimilation efficiency of sago pondweed tubers by tundra swans; $e$ is the energy density $(\mathrm{J} / \mathrm{g})$ of tubers; $t_{h}$ is the handling time $(\mathrm{s} / \mathrm{g})$ (i.e., the time required for a forager to extract the food item from the substrate and consume it); $\varphi(s)$ is the proportion of foraging time spent feeding (s) (i.e., time with head under water), as a function of sediment type $s$; $a(s)$ is the attack rate $\left(\mathrm{m}^{2} / \mathrm{s}\right)$, as a function of sediment type $s$; $D(d)$ is the accessible tuber biomass density $\left(\mathrm{g} / \mathrm{m}^{2}\right)$, as a function of water depth $d$; and $c(d, s)$ is the energetic costs related to foraging $(\mathrm{J} / \mathrm{s})$, as a function of both water depth $d$ and sediment type $s$.

The parameter values in the equation remained largely the same as provided by Nolet and Klaassen (2009). However, we estimated pixel-specific sediment-dependent variables, based on the range of sediment texture indices in our study. Considering the foraging costs and giving-up densities (GUDs), we corrected the regression equations for the switch in foraging modes from head-dipping in shallow water $(\leq 0.51 \mathrm{~m})$ to the more costly up-ending in deep water (Nolet et al. 2006). These corrections included the proportion of foraging time spent feeding (regression equation: $-0.0096 s+0.744)$, attack rate $(-0.000098 s+0.000857)$, foraging cost in shallow water $((0.0721 s+1.1198) \times 45.1)$, foraging cost in deep water $((0.0721 s+1.1198) \times 56.7)$, tuber burial depth profile $(0.0000312 s+0.0008219)$, giving-up density in shallow water $(1.3453 s+11.186)$, and giving-up density in deep water $(3.3632 s+18.891)$. For these calculations, we standardized water depth to the average water level of the period the swans were present at the Lauwersmeer, excluding the days when no swans were foraging due to high water levels. However, as water levels are carefully regulated (SD of $0.16 \mathrm{~m}$ in 2006 and $0.17 \mathrm{~m}$ in 2007) by letting superfluous water to the sea, such days occur only irregularly: in our case on 3 days during 2006 and only 1 day during 2007.

\section{Model Comparison}

We estimated tuber biomass and net energy intake rates per pixel (Figs. 1 and 2). We took GUD values, as a function of sediment type and water depth, from earlier published results (Nolet et al. 2001). We used the burial depth distribution of tuber biomass (Nolet and Klaassen 2009) to calculate the proportion of biomass accessible to swans as a function of water depth and sediment type. Bird numbers are expected to increase proportionally to the natural logarithm of tuber biomass density and net energy intake rate (Nolet and Klaassen 2009). In order to account for this, we subjected both tuber density and net energy intake rates to lntransformation, and summed them per inlet. Nolet and Klaassen (2009) estimated the giving-up net energy intake rate of tundra swans at $56 \mathrm{~J} / \mathrm{s}$, thus only pixels above this value were taken into account for the calculations of net energy intake rate. Subsequently, we used the sum of the lntransformed tuber biomass $(B)$, tuber biomass above a giving-up density $(B+)$, accessible tuber biomass above a giving-up density $\left(a B^{+}\right)$, and net energy intake rates above the giving-up net energy intake rate $(\mathrm{NEI+})$ per inlet in simple linear regressions with the observed bird-days.

Finally, we also estimated bird-days per inlet based on functional-aggregative response models calculated per pixel. The input variables of these models corresponded to the four examined predictor models. Model $B$ was based on initial belowground biomass density $D\left(\mathrm{~g} / \mathrm{m}^{2}\right)$ :

$t=\frac{1}{(3600 \varphi(s))}\left(\frac{1}{a(s)} \ln D+t_{h} D\right) ;$

where $t$ is the foraging time per area $\left(\mathrm{h} / \mathrm{m}^{2}\right)$. Model $B+$ was based on biomass density $\left(\mathrm{g} / \mathrm{m}^{2}\right)$ above the threshold density $D_{f}$ :

$t=\frac{1}{(3600 \varphi(s))}\left(\frac{1}{a(s)} \ln \frac{D}{D_{f}}+t_{h}\left(D-D_{f}\right)\right) ;$

Model $a B+$ was based on accessible biomass density $D(d)$ $\left(\mathrm{g} / \mathrm{m}^{2}\right)$ above the threshold density:

$t=\frac{1}{(3600 \varphi(s))}\left(\frac{1}{a(s)} \ln \frac{D(d)}{D_{f}}+t_{h}\left(D(d)-D_{f}\right)\right) ; \quad$ and 


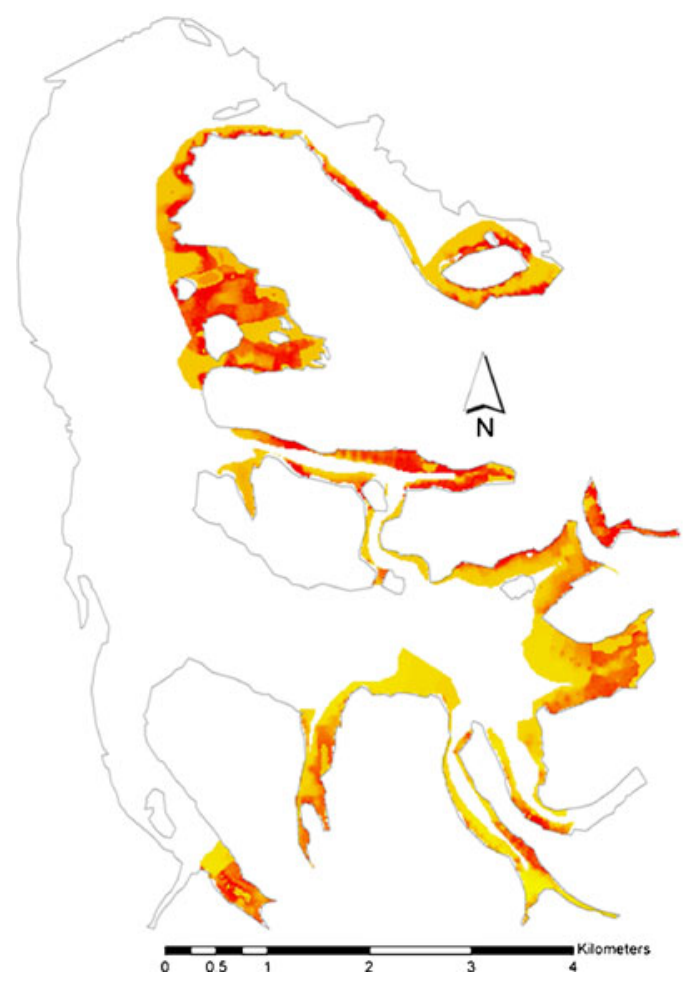

Fig. 2 Map of predicted net energy intake rate for Tundra swans in the Lauwersmeer in 2006 (left) and 2007 (right): the darker the coloring, the higher the net energy intake rate $(2006:-90-360 \mathrm{~J} / \mathrm{s}$;

model $N E I+$ was based on potential net energy intake rate nei $(\mathrm{J} / \mathrm{s})$ above the threshold level of $56 \mathrm{~J} / \mathrm{s}$, based on empirical relationships derived from Fig. $4 \mathrm{c}$ in Nolet and Klaassen (2009):

for sandy inlets : $t=0.3050 . \ln n e i-1.2703$;

and clayey inlets : $t=0.4735$. $\ln n e i-1.9435$.

Finally, we transformed foraging time per area into birddays $S_{i}$ (per inlet) by summing the foraging times estimated per pixel $t_{\mathrm{p}}$ :

$S_{i}=\frac{\left(\sum t_{p} \cdot 225\right)_{i}}{24}$

where 225 serves for converting a pixel into $\mathrm{m}^{2}$ values and 24 for converting hours to days.

\section{Results}

The Malvern analysis of the sediment samples revealed that there was a clear north-south gradient in the Lauwersmeer, with higher proportions of sand (i.e. particles $>63 \mu$ ) in the sediment in the northern inlets and clay in the southern

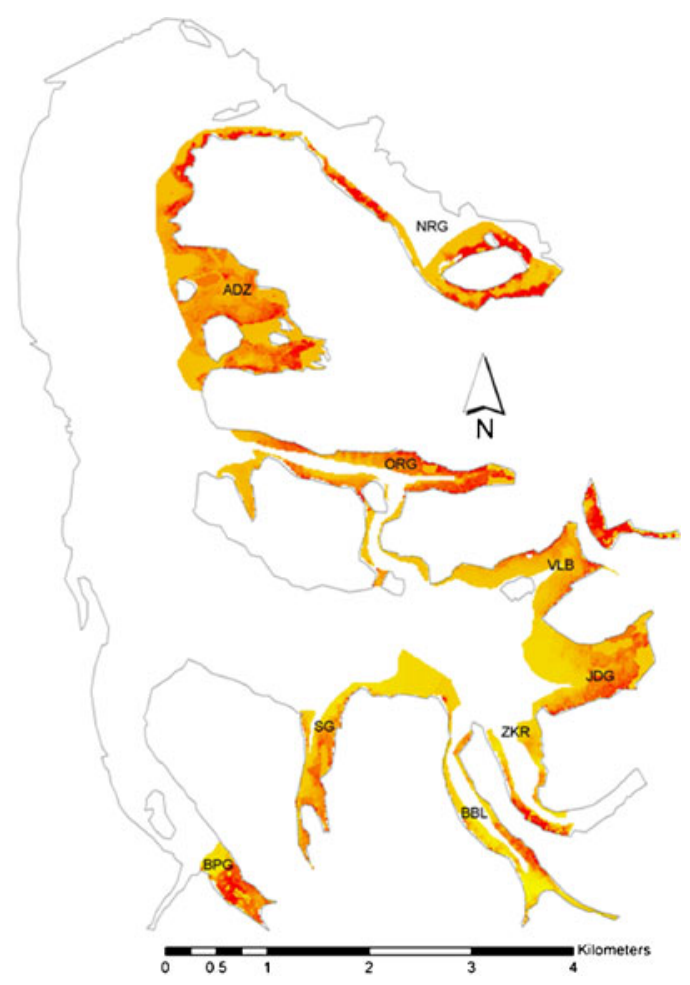

2007: $-90-310 \mathrm{~J} / \mathrm{s})$. The deep parts of the lake $(>1.5 \mathrm{~m})$ are excluded from the analyses and left blank (for abbreviations of the inlets see Fig. 1)

inlets. Total potential foraging area $A$ in the studied inlets varied greatly with year and the applied prediction criteria. In 2006, considering biomass (either all biomass or only the biomass above the giving-up density) provided approximately five times larger potential foraging area and the accessible biomass above the giving-up density 3.6 times larger potential foraging area than considering net energy intake rate above the threshold level. In 2007, the potential foraging area based on biomass estimations was more or less the same as in 2006. However, in 2007, the potential foraging area considering net energy intake rate above the threshold level was around a third of that in 2006.

Based on our samples, aboveground $(P)$ and tuber $(D)$ biomass density showed a positive correlation $(D=0.54 P+$ $\left.0.34 ; \mathrm{F}_{1,75}=39.9 ; r^{2}=0.42 ; P<0.001\right)$. Taking all inlets of the Lauwersmeer into account, the predicted belowground tuber biomass density in 2006 was $15.6 \mathrm{~g} / \mathrm{m}^{2}( \pm 7.2 \mathrm{SD})$ (Fig. 1). The validation carried out on the 20 additional sampling points collected in the autumn of 2006 resulted in a root mean square error (RMSE) of $7.5 \mathrm{~g} / \mathrm{m}^{2}$. In 2007 , the predicted mean tuber biomass density was $7.1 \mathrm{~g} / \mathrm{m}^{2}$ ( $\pm 5.0 \mathrm{SD}$ ) (Fig. 1) with a RMSE value of $8.3 \mathrm{~g} / \mathrm{m}^{2}$ for the validation. Tuber biomass levels were $22-90 \%$ less during 2007 than during 2006 at all inlets, except in the Vlinderbalg, where tuber biomass was greater during 2007 than during 2006 (Fig. 1). 
In 2006, tundra swans were present at the lake from 11 October until 10 November. The mean foraging bird-days per inlet was $734( \pm 310 \mathrm{SE})$, giving a total number of foraging bird-days of 6607 for the lake. In 2007 the exploitation period lasted similarly from 12 October until 16 November. However, the mean foraging bird-days per inlet was only 322 ( $\pm 119 \mathrm{SE})$, adding up to a total of 2898 foraging bird-days, less than half in 2006. Considering all the inlets, the percentage of birds foraging was $47.5 \%( \pm 8.2 \mathrm{SE})$ in 2006 and $49.6 \%$ ( $\pm 9.3 \mathrm{SE})$ in 2007 , which was not significantly different $\left(t_{36}=2.03, P>0.9\right)$. However, the spatial distribution of the birds changed considerably between the 2 years. In 2006 , more than $75 \%$ of the bird-days were spent in two of the nine inlets (Oude Robbengat and Achter de Zwarten). In 2007 , these two inlets accounted for only $33 \%$ of all the birddays, as the swans were more evenly spread among the inlets.

In 2006, our more complex models fit the data better, and in 2007, the most complex one, model $N E I+$, was the only model that fit the data well (Fig. 3). Total accessible biomass above the local GUD (model $a B^{+}$) showed a significant relationship with the observed bird-days per inlet in 2006 (Fig. 3c), but only the total net energy intake above a
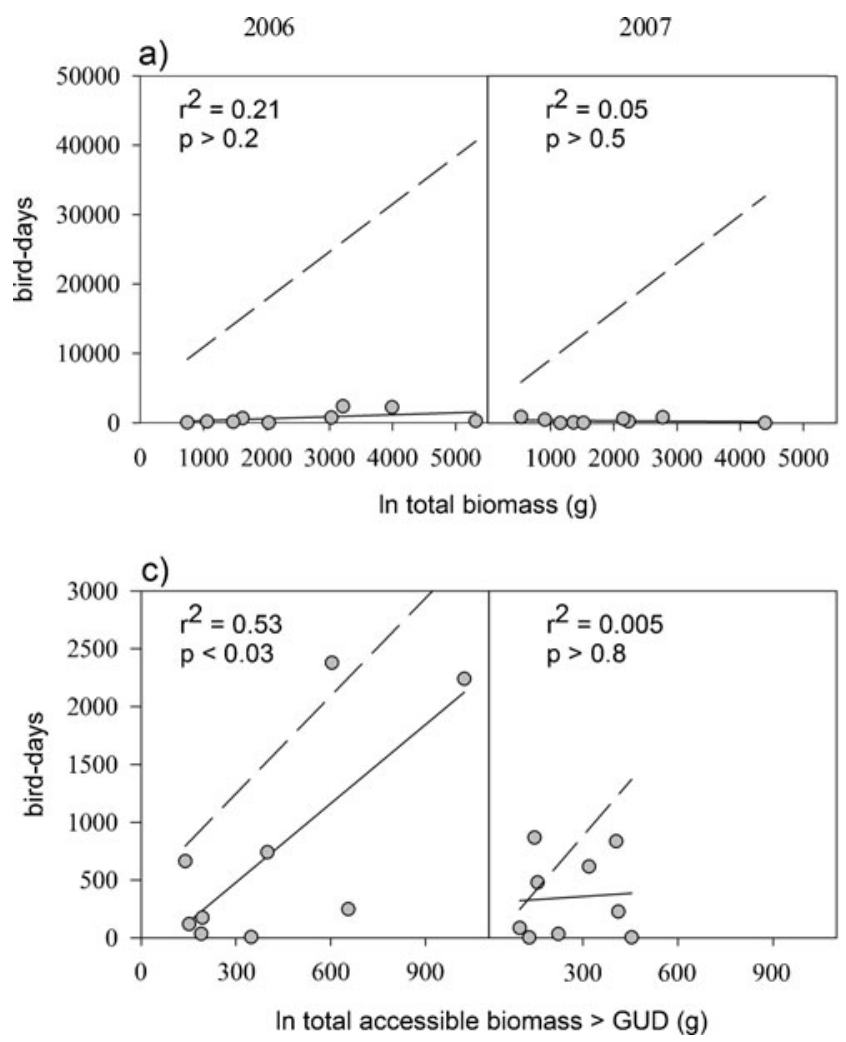

Fig. 3 Simple linear regressions between ln-transformed observed foraging bird-days on four resource measures: a the sum of the (lntransformed) food biomass per inlet, $\mathbf{b}$ the sum of the (ln-transformed) food biomass per inlet above the giving-up density, $\mathbf{c}$ the sum of the accessible (ln-transformed) food biomass per inlet above the giving-up threshold value of $56 \mathrm{~J} / \mathrm{s}$ (model $N E I+$ ) provided a significant correlation in both years (Fig. 3d).

Bird-day estimates derived from the functional-aggregative response models based on total tuber biomass (model $B$ ) provided great overestimations compared to observed birddays (Fig. 3a). This was especially true for creeks where hardly any foraging birds were observed: in these creeks most of the pixels contained a very small amount of food, which resulted in a high cumulative estimate of food resources, and thus bird-days. Similarly, biomass above GUD (model $B+$ ) also resulted in large overestimates of bird-days (Fig. 3b). Although the models based on total accessible biomass above GUD (model $a B+$ ) also produced substantial overestimations, these were more in the range of the observational data, especially in 2006 (Fig. 3c). In this year, this model had a comparable slope to the regression of the observational data, although the intercept was still noticeably different (Fig. 3c). Only the model based on total achievable net energy intake rate above the giving-up net energy intake rate (model $N E I+$ ) yielded good matches between observed and predicted relationships in both years (Fig. 3d).
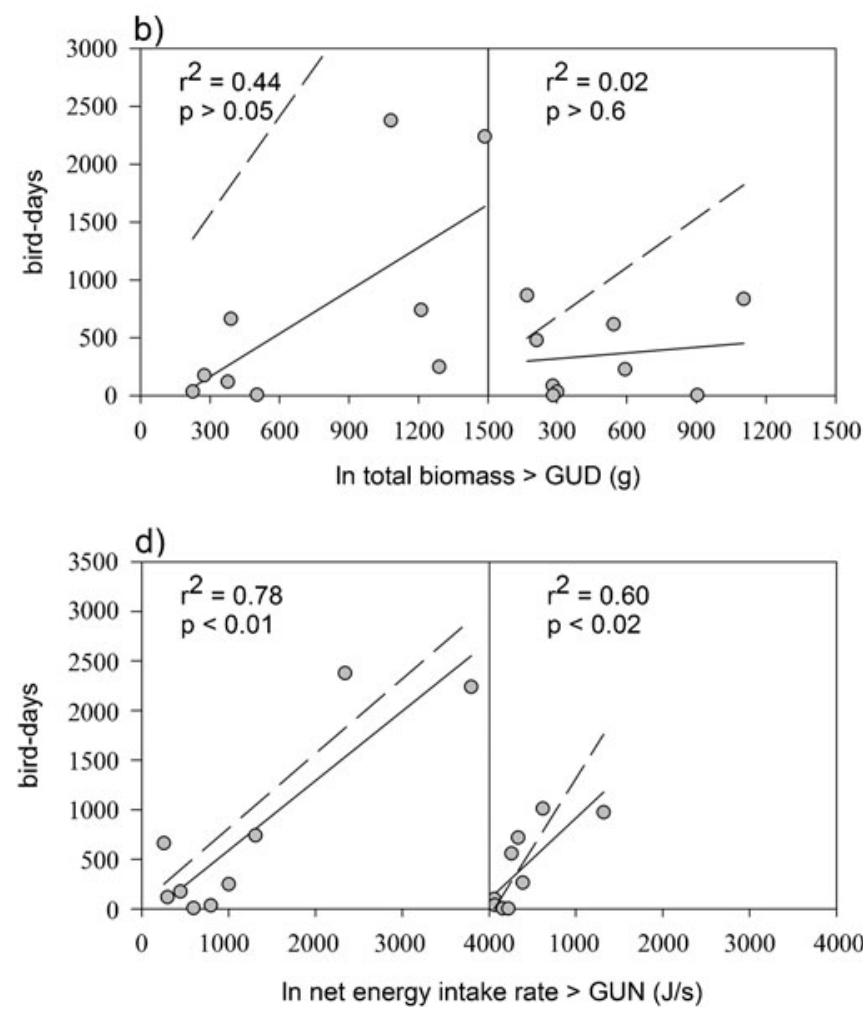

density, and $\mathbf{d}$ the sum of the (ln-transformed) net energy intake rate per inlet above the giving-up net energy intake rate $(56 \mathrm{~J} / \mathrm{s})$. Solid line shows linear regressions (with statistics included per graph); dotted lines provide foraging bird-days predictions based on functional response calculations. Left 2006 and right 2007 


\section{Discussion}

Our case study suggests that in certain cases bird-days may be better predicted by summing net energy intake rates (above the giving-up net energy intake rate below which foraging is more profitable elsewhere) than by more simple measures of food biomass. Among our four candidate predictions of bird-days, the net energy intake rate model was the only one producing significant correlations with observed bird-days in both study years. This implies that food biomass alone, even if corrected for a threshold GUD, may not adequately predict bird distribution in wetlands with a large environmental heterogeneity. This corroborates the conclusion from a theoretical study that predicted that in such areas the spatial variation of factors other than food biomass has to be accounted for (van Gils et al. 2004).

Of the predictions from the functional-aggregative response model, only the ones relying on net energy intake rate reasonably matched observed bird-days in both years, but even those slightly overestimated the observed relationships. Earlier, Nolet and Klaassen (2009) showed that these models adequately predicted bird-days in a small scale setup (four $250 \times 250 \mathrm{~m}$ sections). At such a scale, estimating the actively used foraging area can be carried out more adequately, whereas in our study we had to assume that birds use the total size of sago beds indicated by the satellite images in an ideal way. However, birds may not be able to find all pondweed patches. In addition, foraging in a group may bring about reduced efficiencies (Gyimesi et al. 2010), and thus birds may quit foraging earlier than estimated by functional response models. Finally, some inlets of the Lauwersmeer are open to recreational activities, and may not always be available for swans (Gyimesi, Franken, Feige and Nolet, unpubl. data). Accordingly, our results might be biased if recreational activities are correlated with tuber densities in some way. This suggests the need for further study with sufficient replication to control for disturbance.

Accessibility of food and foraging costs might have a larger influence on feeding site selection in times of resource scarcity. In such cases, net energy intake rate, which also integrates these variables, may be especially suitable to predict bird distribution. In 2007, the tuber biomass was on average less than half of 2006, probably caused by substantial grazing on the aboveground vegetation in the summer by mute swans, mallards, gadwalls, and coots (Gyimesi et al. 2011). In 2007, bird-days were also less than half of 2006, and predictions based on food biomass showed much weaker correlations with observed bird-days in 2007 than in 2006. Moreover, accessible food biomass above GUD (model $a B+$ ) could not properly predict bird-days at the inlet level in 2007, whereas it had some predictive value in 2006 . In 2007 only net energy intake rate could properly predict bird distribution.
Earlier, Gill et al. (2001b) argued that depletion models, relying on non-spatial functional responses, could be used to predict consumer abundances. However, Goss-Custard et al. (2003) pointed out that such models might not be applicable if the foraging sites within one habitat differ greatly. At the Lauwersmeer, food biomass, foraging costs, and accessibility of the food items had a great deal of spatial and temporal variability (Nolet and Klaassen 2009). Moreover, wind fetch and grazing by waterfowl in summer might also affect the development of aboveground biomass differently per inlet and per year (Scheffer et al. 1992; Wersal et al. 2006; Hidding et al. 2009; Gyimesi et al. 2011). Therefore, interannual changes in food density do not have the same direction in all the inlets. Hence, total biomass in the lake may remain the same from 1 year to the next but distributed in a different way.

The effectiveness of using aboveground biomass to predict tuber biomass was limited and was probably even further complicated by herbivory by other waterfowl species. First, grazing on aboveground vegetation late in the summer (after assessing aboveground biomass) affects tuber production (Hidding et al. 2009; Gyimesi et al. 2011). Second, other tuber-eating birds, like diving ducks and coots, may also consume a part of the tuber biomass, thus leave less behind for Bewick's swans (Gyimesi, van Lith and Nolet, unpubl. data). As sampling belowground food resources is laborintensive and time consuming, we also made a compromise in taking only a limited number of cores per sampling plot. Tuber biomass density shows a large variance even on a small scale (Klaassen et al. 2006), thus sampling may be prone to larger errors. However, variations on the scale of some well-spread sampling stations might still give a good picture on overall habitat quality (van der Meer 1997). In order to investigate the foraging decisions swans make on how long to stay in an inlet (30-150 ha), we scaled up from small sampling plots, which might have hidden errors on the small scale.

Additionally, our spatially-explicit variables, and consequently our final correlations, rely on a series of interpolations or are derived from estimations. For instance, sediment texture was defined by linear regressions between sandy and clayey sediments, based on agriculturaloriented studies to calculate the power requirements of loosening soils of different compaction levels (Alimardani et al. 2007). In order to incorporate these estimates in our models, we had to assume that these were measured without error, despite the fact that there was error associated with each estimate. Accordingly, our models underestimate the variability in our system and are generally expected to have a smaller likeliness of a strong relationship between predicted and observed values. This would especially hold for our more complicated models. Nonetheless, the most complicated model was the only one providing a significant 
relationship in both years, in support of our interpretation of results.

All the tested models rely on the assumption that birds are free to choose their foraging site. However, competition may also influence site selection because interference likely reduce food intake rates (Sutherland 1983; Janson and Goldsmith 1995; Gyimesi et al. 2010). In addition, deeper inlets may be abandoned earlier than shallower ones if water level increases. Finally, human disturbance also can seriously affect the distribution of birds (see e.g. Gill et al. 1996). Animals might trade-off safety with energetic returns, resulting in shorter exploitation times at sites perceived to be more risky (Brown et al. 1994; Gill et al. 1996; van Gils and Tijsen 2007). The magnitude of this effect might change with the amount of food present. In years of low resource abundance, animals might be more willing to forage in higher-risk habitats (Inger et al. 2006; Godvik et al. 2009). This phenomenon might be enhanced if summer herbivores also avoid disturbed inlets, which would result in locally higher tuber densities (Hidding et al. 2009; Gyimesi et al. 2011). Incorporating such variables in future models may further improve predictions of bird distribution and abundance.

The findings of our case study may have important implications for carrying capacity assessments of wetlands. Firstly, in heterogeneous systems, reliance on food biomass only, without considering a threshold or accessibility, can lead to overestimations of carrying capacity. Large areas with food biomass below the giving-up density or with biomass out of reach can be of limited value for animals. In addition, sites with high biomass levels but with high foraging costs are also less frequented. In such cases, applying net energy intake rate as a predictor for animal distribution and abundance can help managers of aquatic resources to identify important or critical areas, and to assess impacts of various developments upon migratory waterbirds (Ma et al. 2010). In addition, incorporating net energy intake rate predictions may improve estimates of carrying capacity of wetlands, if models can be developed that can incorporate variability of model inputs. Furthermore, managers may be able to better adjust water levels to maximize carrying capacity of wetlands similar to the one highlighted in our case study.

Acknowledgments We thank Staatsbosbeheer, and especially Jan Willems, for allowing us to work in the area of the Lauwersmeer. We want to express our gratefulness to Koos Swart, Boris Arévalo, Mariska Nieuwenhuijsen, Susan Zwerver, Rommert Cazemier, Oane Tol, Nicole Feige, Lucia Galiano Pérez, Steffen Hahn, Bert Hidding, Marcel Klaassen and Casper van Leeuwen for assistance during the field trips. Boris Arévalo worked on earlier versions of the satellite image analysis. Special thanks to Thijs de Boer and Peter de Vries for organizing and leading the fieldwork, and also analyzing all plant and sediment samples. Marcel Klaassen, Theunis Piersma, Don Peden, Darold Batzer and three anonymous reviewers gave valuable feedback on the manuscript. AGy was financed by the Netherlands Organization for Scientific Research (NWO-ALW grant 814.01.008 to BAN). This is publication 5133 of the Netherlands Institute of Ecology (NIOO-KNAW).

Open Access This article is distributed under the terms of the Creative Commons Attribution Noncommercial License which permits any noncommercial use, distribution, and reproduction in any medium, provided the original author(s) and source are credited.

\section{References}

Alimardani R, Abbaspour-Gilandeh Y, Khalilian A, Keyhani A, Sadati SH (2007) Energy savings with variable-depth tillage "A precision farming practice". American-Eurasian Journal of Agricultural \& Environmental Sciences 2:442-447

Beekman JH, van Eerden MR, Dirksen S (1991) Bewick's Swans Cygnus columbianus bewickii utilising the changing resource of Potamogeton pectinatus during autumn in the Netherlands. Wildfowl Supplement 1:238-248

Brown JS (1988) Patch use as an indicator of habitat preference, predation risk, and competition. Behavioral Ecology and Sociobiology 22:37-47

Brown JS, Kotler BP, Valone TJ (1994) Foraging under predation-a comparison of energetic and predation costs in rodent communities of the Negev and Sonorian deserts. Australian Journal of Zoology 42:435-448

Charnov EL (1976) Optimal foraging, the marginal value theorem. Theoretical Population Biology 9:129-136

de Leeuw JJ, van Eerden MR, Visser GH (1999) Wintering tufted ducks Aythya fuligula diving for zebra mussels Dreissena polymorpha balance feeding costs within narrow margins of their energy budget. Journal of Avian Biology 30:182-192

Gill JA, Sutherland W, Watkinson AR (1996) A method to quantify the effects of human disturbance on animal populations. Journal of Applied Ecology 33:786-792

Gill JA, Norris K, Sutherland WJ (2001a) The effects of disturbance on habitat use by black-tailed godwits Limosa limosa. Journal of Applied Ecology 38:846-856

Gill JA, Sutherland WJ, Norris K (2001b) Depletion models can predict shorebird distribution at different spatial scales. Proceedings of the Royal Society of London Series B-Biological Sciences 268:369-376

Godvik IMR, Loe LE, Vik JO, Vr V, Langvatn R, Mysterud A (2009) Temporal scales, trade-offs, and functional responses in red deer habitat selection. Ecology 90:699-710

Goss-Custard JD (1985) Foraging behaviour of wading birds and the carrying capacity of estuaries. In: Sibly RM, Smith RH (eds) Behavioural ecology: ecological consequences of adaptive behaviour. Blackwells, Oxford, pp 169-188

Goss-Custard JD, Stillman RA, Caldow RWG, West AD, Guillemain M (2003) Carrying capacity in overwintering birds: when are spatial models needed? Journal of Applied Ecology 40:176-187

Gyimesi A, Stillman RA, Nolet BA (2010) Cryptic interference competition in swans foraging on cryptic prey. Animal Behaviour 80:791-797

Gyimesi A, de Vries PP, de Boer T, Nolet BA (2011) Reduced tuber banks of fennel pondweed due to summer grazing by waterfowl. Aquatic Botany 94:24-28

Hangelbroek HH, Santamaría L (2004) Regulation of propagule size in the aquatic pseudo-annual Potamogeton pectinatus: are genetic and maternal non-genetic effects additive? Evolutionary Ecology Research 6:147-161 
Hidding B, Nolet BA, de Boer T, de Vries PP, Klaassen M (2009) Compensatory growth in an aquatic plant mediates exploitative competition between seasonally tied herbivores. Ecology 90:1891-1899

Hidding B, Nolet BA, de Boer T, de Vries PP, Klaassen M (2010) Above- and below-ground vertebrate herbivory may each favour a different subordinate species in an aquatic plant community. Oecologia 162:199-208

Houston AI, Carbone C (1992) The optimal allocation of time during the diving cycle. Behavioral Ecology 3:255-265

Huisman J, Olff H, Fresco LFM (1993) A hierarchical set of models for species response analysis. Journal of Vegetation Science 4:37-46

Inger R, Bearhop S, Robinson JA, Ruxton G (2006) Prey choice affects the trade-off balance between predation and starvation in an avian herbivore. Animal Behaviour 71:1335-1341

Janson CH, Goldsmith ML (1995) Predicting group sizes in primates: foraging costs and predation risks. Behavioral Ecology 6:326-336

Johnstone I, Norris K (2000) The influence of sediment type on the aggregative response of oystercatchers, Haematopus ostralegus, searching for cockles, Cerastoderma edule. Oikos 89:146-154

Klaassen RHG, Nolet BA, Bankert D (2006) Movement of foraging tundra swans explained by spatial pattern in cryptic food densities. Ecology 87:2244-2254

Kraan C, Van Gils JA, Spaans B, Dekinga A, Bijleveld AI, van Roomen M, Kleefstra R, Piersma T (2009) Landscape-scale experiment demonstrates that Wadden Sea intertidal flats are used to capacity by molluscivore migrant shorebirds. Journal of Animal Ecology 78:1259-1268

Ma Z, Cai Y, Li B, Chen J (2010) Managing wetland habitats for waterbirds: an international perspective. Wetlands 30:15-27

Newton I (1980) The role of food in limiting bird numbers. Ardea 68:11-30

Nolet BA, Klaassen M (2005) Time and energy constraints in demanding phases of the annual cycle: an example of time limitation in refuelling migratory swans. Oikos 111:302-310

Nolet BA, Klaassen M (2009) Retrodicting patch use by foraging swans in a heterogeneous environment using a set of functional responses. Oikos 118:431-439

Nolet BA, Bevan RM, Klaassen M, Langevoord O, van der Heijden Y (2002) Habitat switching by Bewick's swans: maximization of average long-term energy gain? Journal of Animal Ecology 71:979-993

Nolet BA, Langevoord O, Bevan RM, Engelaar KR, Klaassen M, Mulder RJW, van Dijk S (2001) Spatial variation in tuber depletion by swans explained by differences in net intake rates. Ecology 82:1655-1667

Nolet BA, Fuld VN, van Rijswijk MEC (2006) Foraging costs and accessibility as determinants of giving-up densities in a swanpondweed system. Oikos 112:353-362
Percival SM, Evans PR (1997) Brent Geese Branta bernicla and Zostera; Factors affecting the exploitation of a seasonally declining food resource. Ibis 139:121-128

Percival SM, Sutherland WJ, Evans PR (1998) Intertidal habitat loss and wildfowl numbers: applications of a spatial depletion model. Journal of Applied Ecology 35:57-63

Pot R (1984) The development of Potamogeton vegetation in the Lauwersmeer. Acta Botanica Neerlandica 33:361-362

Price D (1999) Carrying capacity reconsidered. Population and Environment 21:5-26

Ricker WE (1984) Computation and uses of central trend lines. Canadian Journal of Zoology-Revue Canadienne De Zoologie 62:1897-1905

Salewski V, Schaub M (2007) Stopover duration of Palearctic passerine migrants in the Western Sahara - independent of fat stores? Ibis 149:223-236

Sayre NF (2008) The genesis, history, and limits of carrying capacity. Annals of the Association of American Geographers 98:120-134

Scheffer M, de Redelijkheid MR, Noppert F (1992) Distribution and dynamics of submerged vegetation in a chain of shallow eutrophic lakes. Aquatic Botany 42:199-216

Stephens DW, Krebs JR (1986) Foraging theory. Princeton University Press, Princeton

Sutherland WJ (1983) Aggregation and the ideal free distribution. Journal of Animal Ecology 52:821-828

Sutherland WJ, Anderson CW (1993) Predicting the distribution of individuals and the consequences of habitat lost: the role of prey depletion. Journal of Theoretical Biology 183:223-230

van der Meer J (1997) Sampling design of monitoring programmes for marine benthos: a comparison between the use of fixed versus randomly selected stations. Journal of Sea Research 37:167-179

van Gils JA, Tijsen W (2007) Short-term foraging costs and long-term fueling rates in central-place foraging swans revealed by giving-up exploitation times. American Naturalist 169:609-620

van Gils JA, Edelaar P, Escudero G, Piersma T (2004) Carrying capacity models should not use fixed prey density thresholds: a plea for using more tools of behavioural ecology. Oikos 104:197-204

van Wijk RJ (1988) Ecological studies on Potamogeton pectinatus L. I. General characteristics, biomass production and life cycles under field conditions. Aquatic Botany 31:211-258

Wersal RM, Madsen JD, McMillan BR, Gerard PD (2006) Environmental factors affecting biomass and distribution of Stuckenia pectinata in the Heron Lake System, Minnesota, USA. Wetlands 26:313-321

West AD, Goss-Custard JD, DitDurell SEALV, Stillman RA (2005) Maintaining estuary quality for shorebirds: towards simple guidelines. Biological Conservation 123:211-224

Zwarts L, Wanink JH (1993) How the food-supply harvestable to waders in the Wadden Sea depends on the variation in energy density, body-weight, biomass, burying depth and behavior of tidal-flat invertebrates. Netherlands Journal of Sea Research 31:441-476 